\title{
"No meio do caminho, o rejeito: as problemáticas da mineração no contexto das catástrofes de Mariana e Brumadinho"
}

\author{
Sérgio Luiz Gusmão Gimenes Romero ${ }^{1}$ \\ Rafael Otavio Fares Ferreira ${ }^{2}$
}

Produzir um dossiê capaz de contribuir de maneira relevante para o debate crítico e o conhecimento científico acerca de problemática tão complexa e urgente não constitui, de modo algum, tarefa fácil. Sobretudo em se tratando de um periódico que, em cenário tão adverso à produção acadêmica e à reflexão fundamentada, luta para se consolidar como um instrumento substantivo de compartilhamento de saberes e de mediação entre o arcabouço científico e os interesses sociais.

Talvez possa-se justificar nossa disposição em encampar essa difícil empreitada justamente por um senso de responsabilidade e de compromisso para com uma sociedade tão impunemente violentada pelo apetite voraz com que as todo-poderosas corporações mineradoras preterem vidas em prol de lucros. Dessa forma, assumimos plenamente o bordão tornado célebre pelo filósofo italiano Antonio Gramsci: "É necessário criar homens sóbrios, pacientes, que não se desesperem diante dos piores horrores e não se exaltem em face de qualquer tolice. Pessimismo da inteligência, otimismo da vontade". (2006, p. 267, grifo nosso)

De fato, as disjunções e os conflitos entre, de um lado, os interesses hegemônicos do setor de mineração no país e, de outra parte, o bem-estar e os direitos das populações que

\footnotetext{
${ }^{1}$ Graduado em Letras e Mestre em Estudos Literários pela Faculdade de Ciências e Letras da UNESP, Campus Araraquara. Doutorando em Letras pela Universidade Federal de Minas Gerais - UFMG. É professor e pesquisador da Universidade do Estado de Minas Gerais - UEMG, Unidade João Monlevade, MG, Brasil. Email: sergio.romero@uemg.br.

${ }^{2}$ Graduado, Mestre e Doutor em Letras pela Universidade Federal de Minas Gerais - UFMG. É poeta e também professor e pesquisador da Universidade do Estado de Minas Gerais - UEMG, Unidade João Monlevade, MG, Brasil. E-mail: rafael.ferreira@uemg.br.
} 
habitam o território nacional não constituem, obviamente, uma novidade. Sem embargo, os últimos cinco anos, nos parece, explicitam, em vários aspectos, um aprofundamento dessas contradições.

O marco notório desta fase crítica encontra-se no terrível desastre - crime para uns, incidente para outros — do rompimento da barragem de Fundão em Bento Rodrigues, subdistrito pertencente ao município de Mariana, Minas Gerais, em 5 de novembro de 2015. Tal ocorrência foi responsável pela liberação de 62 milhões de $\mathrm{m}^{3}$ de rejeitos que deixaram um rastro, em muitos aspectos irreversível, de destruição ecológica, humana e social, sobretudo ao longo da bacia do Rio Doce.

Um novo rompimento, novamente catastrófico, em Brumadinho - MG, em 25 de janeiro de 2019, despejou 12 milhões de $\mathrm{m}^{3}$ de rejeitos na bacia do rio Paraopeba, causando pelo menos 259 mortes humanas já confirmadas.

Ambas as recentes catástrofes foram responsáveis pela destruição de centenas de hectares de Mata Atlântica - bioma do qual restam, hoje, apenas 12,4\% de sua extensão original em território brasileiro. Os rompimentos também devastaram afluentes importantes de suas respectivas bacias hidrográficas, Rio Doce e Paraopeba, comprometendo a qualidade hídrica e da biota ao longo de quilômetros de extensão fluvial.

Esses não foram os primeiros rompimentos de barragem de rejeitos de mineração com consequências graves no Brasil e, particularmente, no estado de Minas Gerais. Desde o ano 2000 houve oito rompimentos de barragens de mineração somente neste ente federativo. Todavia, dadas as suas proporções, as ocorrências de 2015 e 2019 intensificaram ainda mais o debate, que há anos vem se desdobrando em relação ao setor, no que tange a seus impactos socioeconômicos, ecológicos e culturais; extrapolando, dessa maneira, os limites de uma abordagem exclusivamente tecnicista e/ou tecnológica das problemáticas da atividade mineradora.

Com efeito, quaisquer expectativas de uma mudança significativa de rumos no setor minerador após a catástrofe de 2015 submergiram na lama de rejeitos do já mencionado rompimento da barragem da Vale, no Córrego do Feijão, em 2019. E, a despeito dessa somatória de tragédias, os desdobramentos subsequentes não delineiam uma realidade menos perigosa.

Na verdade, ao rompimento da barragem de Fundão em 2015 sucederam-se ações governamentais a nível estadual e federal no sentido de flexibilizar e acelerar ainda mais processos de aprovação de licenças para a mineração. Entre as medidas representativas desse 
movimento cabe assinalar a Lei Estadual 21.972/2016, aprovada, em janeiro de 2016, pela Assembleia Legislativa de Minas Gerais; o Decreto 47.137 de janeiro de 2017, expedido pelo governador do mesmo estado; bem como a aprovação, pela Comissão de Constituição, Justiça e Cidadania do Senado, da Proposta de Emenda Constitucional 65/2012 em abril de 2016. (ZHOURI et al., 2018)

Esse quadro aterrador não pode ser minimamente analisado sem um efetivo esforço de compreensão das relações dialéticas que se estabelecem entre conflitos e contradições territorialmente localizados e o cenário econômico global. De fato, não é por acaso que a intensificação quantitativa e qualitativa de acidentes no campo da mineração tem lugar justamente no contexto do pós-boom das commodities minerais, sobretudo a partir de 2012.

Do início dos anos 2000 até meados de 2011, temos o chamado boom do setor. Neste período, em resposta ao expressivo crescimento da demanda internacional, o minério de ferro, por exemplo, passa por uma valorização, no mercado internacional, de quase quinze vezes em uma década; ao passo que sua importação global se eleva, de 2011 a 2014, em 178\%. Tal processo fez com que o extrativismo mineral assumisse um pronunciado protagonismo na pauta exportadora de países como o Brasil, ajudando a garantir, com a expansão das atividades mineradoras, os superávits de suas balanças comerciais. (WANDERLEY, 2017)

Em contrapartida, no pós-boom que se instaura a partir de 2012, verifica-se claramente um movimento das grandes corporações do setor no sentido de tentar compensar a intensa queda nos preços e, assim, manter a salvo os interesses dos acionistas. Dessa forma, em frente à baixa dos preços e da demanda global, o esforço por manter as taxas de lucro por meio do aumento da produtividade e da redução dos custos de operação - se pauta, em grande medida, pelo incremento no grau de exploração da força de trabalho, assim como pelos cortes de custos com preservação ambiental e responsabilidade social.

As tragédias de Mariana e Brumadinho são, desse modo, o resultado incontornável de um processo anterior bem demarcado. Quando se prioriza a manutenção das exorbitantes taxas de ganhos do mercado do setor minerário por meio do aceleramento da exploração humana e ecológica, aliada ainda à redução de gastos com prevenção e preservação ambiental, fica difícil imaginar consequências menos funestas.

Mas também não é menos grave a situação presente, haja vista o número de barragens de rejeitos de mineração sem estabilidade ter passado de 21 em 2019 para 38 em 2020; ou 
seja, atualmente, 9\% das barragens monitoradas pela Agência Nacional de Mineração no país estão em condições não estáveis. (MILANEZ; WANDERLEY, 2020)

Soma-se a isso a precarização da própria Agência Nacional de Mineração e, por conseguinte, o comprometimento das atividades de gestão e regulação do setor a ela imbuídas. Na realidade, a autarquia vinculada ao Ministério de Minas e Energia vem sofrendo ano após ano e sobretudo no atual governo com reduções em seu orçamento que comprometem temerariamente sua missão de fiscalizar processos de extração mineral, incluídas aí as condições das barragens de rejeitos catalogadas em todo o território nacional. (MILANEZ; WANDERLEY, 2020)

Nesse sentido, as noções de desenvolvimento e progresso bem como as atividades econômicas baseadas no extrativismo de larga escala têm sido, por diferentes caminhos teóricos, políticos e científicos, colocadas crescentemente em xeque; uma vez que se explicita, de maneira cada vez mais contundente, a discrepância entre, por um lado, a quantidade de riquezas engendradas pela exploração de gigantescos volumes de recursos naturais em países de capitalismo periférico e, por outro, a trágica contraparte social e ecológica desse extrativismo massivo que recai sobre essas nações, cuja economia é dependente, em grande medida, das exportações das commodities.

Sob esse viés, a síntese crítica do economista equatoriano Alberto Acosta nos parece vigorosamente acertada:

\begin{abstract}
A economia extrativista deteriora grave e irreversivelmente o meio ambiente. $\mathrm{O}$ estudo da atividade mineradora ou petrolífera ao redor do planeta evidencia inúmeros danos e destruições múltiplas e irreversíveis à Natureza. Além disso, são incontáveis as tragédias humanas e a destruição de potencialidades culturais dos povos. No âmbito econômico, a situação não é melhor. Os países cujas exportações dependem fundamentalmente de recursos minerais ou petrolíferos são economicamente atrasados, e seus problemas ambientais crescem no ritmo em que se expande o extrativismo. (2016, p. 61-62)
\end{abstract}

Aqui, nos parece apropriado ainda retomar um pequeno poema de Carlos Drummond de Andrade, o qual, por meio da percepção estética alinhada com uma apreensão crítica de uma realidade que o itabirano conhecia muito bem, cristaliza a tragédia continuada que cai e recai sobre todos nós:

\title{
INFATIGÁVEL
}

O progresso não recua.

Já transformou esta rua

em buraco. 
E o progresso continua.

Vai abrir neste buraco outra rua.

Afinal, da nova rua, o progresso vai compor outro buraco.

(2014, p. 120)

Nesse texto, a ironia sutil, característica do discurso drummondiano, articula crítica e pessimismo para desmantelar o mito do progresso tão afim ao regime ditatorial então implantado no país. Com efeito, "Infatigável" - cujo título adjetiva o avanço do progresso e baliza a leitura do poema - foi publicado em 1977, no bojo de um arsenal de textos poéticos e jornalísticos do ilustre itabirano que se ocupavam de desnudar um momento histórico marcado pela corrosão ambiental, cultural, social e econômica levada a cabo pela atuação do setor minerador conjugado com uma ditadura civil-militar que fez da barbárie seu modus operandi por duas décadas no Brasil. (ROMERO, 2020)

No pequeno poema, a repetição, ao longo das três estrofes, da tríade: progresso, rua e buraco reforçam o caráter ciclicamente destrutivo de processos que, sob a égide de sonoros e belos bordões - tais como "progresso", "desenvolvimento" e "crescimento econômico" — só atingem o meio ambiente e a imensa maioria da população pelo seu revés.

Ora, não é justamente essa a dinâmica a que temos sido submetidos pela atuação das grandes redes corporativas do setor de mineração nos últimos anos? Mostra-se bem apropriado, em consonância com a perspectiva enunciada por Drummond e à luz dos desastres ocorridos, recuperar a concepção de "progresso" assinalada pelo filósofo alemão Walter Benjamin, segundo o qual: "Deve-se fundar o conceito de progresso na ideia da catástrofe. Que tudo “continue assim”, isto é a catástrofe. Ela não é o sempre iminente, mas sim o sempre dado" $(1995,174)$.

Por outro lado, o mesmo trágico cenário cujos contornos opressores buscamos aqui delinear também enseja resistências. Dessarte, à medida que o colapso socioambiental se mostra mais e mais a estação próxima e final a que, inexoravelmente, nos conduz o célere trem do progresso capitalista; fervilham e transbordam também ações que convergem em divergir do statu quo - experiências coletivas, tradições alternativas e ideias para adiar o fim do mundo.

Entre essas vozes que mais do que nunca se fazem ouvir, destacam-se, entre outras: 
O Movimento dos Atingidos por Barragens - MAB: organização pioneira na defesa, articulação e mobilização de populações atingidas pela implantação de projetos de barragens — seja de hidrelétricas seja de rejeitos de mineração — e que atua desde a década de oitenta no país. O MAB se destaca por sua construção coletiva, pelo questionamento radical das políticas e dinâmicas energéticas no país e pela defesa intransigente dos direitos dos atingidos.

Ademais, evidencia-se o trabalho desenvolvido, desde 2008, pelo "Movimento pelas Serras e Águas de Minas" - MovSAM. Esse movimento socioambiental tem desempenhado um importante papel na defesa da água e do meio ambiente enquanto patrimônios públicos fundamentais do estado, bem como efetuado sistematicamente a denúncia das ingerências e autoritarismos que configuram a ação de elites político-econômicas vinculadas à mineração no país.

Em consonância, assinala-se a atividade da Articulação Internacional dos Atingidos e Atingidas pela Vale - AIAAV. Essa organização congrega, desde 2009, diferentes categorias: movimentos sociais, sindicalistas, ambientalistas, ONGs, associações comunitárias, grupos acadêmicos etc., do Brasil e de outros países em que a Vale S.A. atua, com o fito de fortalecer redes de enfrentamento dos impactos da lógica extrativista promovida pela multinacional.

Outra organização popular de atuação substantiva no país é o Movimento pela Soberania Popular na Mineração - MAM. Surgido em 2012, no estado do Pará, o MAM fomenta a organização e a resistência, sobretudo, de povos campesinos, indígenas, quilombolas e ribeirinhos, entre outros, diante da expansão do atual modelo minerador sobre os territórios e sua consequente degradação social e ambiental em nome da acumulação massiva de capital destinado ao mercado financeiro.

Outrossim, merece destaque a recentemente criada Frente Mineira de Luta das Atingidas e dos Atingidos pela Mineração - FLAMa-MG. A proposta essencial dessa organização consiste justamente em conjugar múltiplas mobilizações, posicionamentos e setores da sociedade que concorrem, atualmente, para o enfrentamento dos abusos cometidos por empreendimentos mineradores sobre os territórios em que estes operam.

Perante a atual conjuntura, o presente dossiê materializa o propósito da Revista Engenharia de Interesse Social - REIS de contribuir para a reflexão crítica acerca da problemática da mineração no país e, particularmente, no estado de Minas Gerais. 
Nesse sentido, o artigo "Relações de trabalho na mineração: análise dos acordos coletivos firmados entre o Sindicato Metabase Inconfidentes e a Vale S.A. com validade no período de 2009 a 2018" propõe, a partir da ótica da Teoria Marxista da Dependência, uma análise dos contornos assumidos pela luta de classes, durante o período assinalado, nos acordos coletivos firmados entre o Sindicato Metabase Inconfidentes e a Vale S.A. Com efeito, o recorte adotado pelo trabalho se insere no esforço mais amplo de desnudar, científica e politicamente, o modo como a mineração extrativista na região implica uma dinâmica de dependência econômica, de superexploração da força de trabalho e de devastação do meio ambiente.

De outra parte, o artigo "Análise da mancha de inundação da Barragem Sul da mina de Brucutu, São Gonçalo do Rio Abaixo, MG” apresenta os dados de uma simulação de rompimento da Barragem Sul da Mina Brucutu, em São Gonçalo do Rio Abaixo - MG. Esse trabalho traz apontamentos importantes no que diz respeito tanto às barragens de rejeitos de mineração quanto às situações de emergência provenientes de rompimentos. Indica-se ainda que a forma pela qual os dados fornecidos pelo Plano de Ação de Emergência Para Barragens de Mineração (PAEBM), da empresa responsável pela estrutura da Barragem Sul, são apresentados para a sociedade pode acarretar um desconhecimento, por parte das comunidades atingidas, de nuances vitais de uma eventual situação de ruptura.

Já o texto "Epidemia de febre amarela na bacia do Rio Doce: análise de fatores ambientais, epidemiológicos e efeitos indiretos do rompimento da barragem de Fundão (Samarco S/A)" se dedica a investigar uma possível relação entre o rompimento da barragem de rejeitos de Fundão, em Mariana - MG, em novembro de 2015 e a epidemia de febre amarela surgida no início de 2017, da qual parte significativa das ocorrências foi verificada na região da bacia do Rio Doce. Embora os dados obtidos não atestem uma correlação causal imediata entre os fenômenos, fatores ambientais e epidemiológicos sugerem implicação indireta dos danos ambientais causados pelo rompimento na configuração da epidemia.

Por sua vez, o artigo "Análise das mudanças do uso e da cobertura da terra em municípios com áreas de mineração na microrregião de Itabira a partir de dados do MAPBIOMAS entre 1987 e 2017" reforça a importância do monitoramento do uso do espaço geográfico em regiões mineradoras, a fim de se mensurar aspectos socioambientais, bem como a relação entre a dependência da extração mineral e a diversificação econômica dessas localidades. 
Afinal, o texto "Saberes ambientais nos livros indígenas: uma proposta de educação ambiental a partir das árvores" sinaliza o caminho para a necessária articulação entre a engenharia ambiental e os saberes tradicionais indígenas. $\mathrm{O}$ trabalho toma as árvores como mote para propor ações educativas que transcendam os estéreis lugares-comuns da educação ambiental e os esvaziados discursos acerca da sustentabilidade que se replicam, diuturnamente, à nossa volta, mas que pouco contribuem para barrar o avanço da devastação ecológica. Dessarte, reitera um ponto fundamental das reflexões que urgentemente se nos impõem: os povos da floresta, contra quem o capital minerador esforça-se por avançar implacavelmente, têm muito a nos ensinar sobre existir e resistir.

Analogamente, temos a resenha do livro Ideias para adiar o fim do mundo, de Ailton Krenak. Publicada em 2019, a obra sucinta traz a marca e o estilo de seu autor, uma das mais vigorosas vozes indígenas do país, cuja reflexão incisiva se sobressai pela capacidade ímpar de deslocar nosso olhar, desarticulando o entorpecimento em que concepções e afetos se encontram hoje imersos. Aqui, Ailton Krenak coloca o dedo na ferida, questionando a própria noção de humanidade, tão naturalizada quanto esvaziada de sentido, ao mesmo tempo em que, a partir da experiência de destruição do rio Watu (Rio Doce) - sagrado para os Krenak - , pelo rompimento da barragem de Fundão em Bento Rodrigues em 2015, sinaliza para a necessidade de nos vermos como parte de conjunções que nos abarcam e nos transcendem.

Concluindo o presente dossiê, temos uma entrevista realizada com Camila Leal, advogada popular do Movimento Águas e Serras de Casa Branca. Camila Leal é moradora de Casa Branca, Brumadinho - MG, atuando, também, na Associação Comunitária Regional de Casa Branca, na Associação Comunitária do Jardim Canadá no Parque Estadual da Serra do Rola Moça; e como integrante do Coletivo de Atingidos da Arquidiocese de Belo Horizonte. As substantivas contribuições da entrevistada para se pensar criticamente a problemática proposta nascem da intersecção entre reflexão intelectual e experiência humana, reiterando que a dimensão catastrófica da extração mineral predatória não pode ser reduzida ao âmbito quantitativo.

Em outras palavras, não se trata tão somente de considerar os milhões de $\mathrm{m}^{3}$ de rejeitos responsáveis pelo assassínio de rios e bacias hidrográficas, as centenas de vítimas humanas, as incontáveis vidas exterminadas na flora e na fauna, a degradação de incontáveis quilômetros de ambientes, espaços, ecossistemas, bem como o soterramento de memórias, histórias, saberes e formas de experiência humana. Na verdade, o passivo ecológico e social 
que constituem o legado do extrativismo minerador para a totalidade de nossas sociedades manifesta um caráter qualitativo que transborda qualquer análise e que escapa a qualquer síntese. Essa catástrofe continuada, retomando aqui imagens caras a Walter Benjamin, demanda de nós uma interrupção urgente, pois "[a]ntes que a centelha chegue à dinamite, é preciso que o pavio seja cortado" (BENJAMIN, 1987, p. 46). Se não nos mostrarmos capazes de puxar o freio de emergência antes de certo momento cada vez mais próximo - e a história recente deixa isso muito claro - o trem do progresso nos arrastará para o buraco-abismo definitivo do colapso humano e ambiental.

\section{REFERÊNCIAS}

ACOSTA, Alberto. "Extrativismo e neoextrativismo: Duas faces da mesma maldição". In: DILGER, Gerhard; LANG, Miriam; PEREIRA FILHO, Jorge (orgs.). Descolonizar o imaginário: Debates sobre pós-extrativismo e alternativas ao desenvolvimento. São Paulo: Fundação Rosa Luxemburgo, 2016.

BENJAMIN, Walter. "Alarme de incêndio". In: escolhidas, vol. II. São Paulo: Editora Brasiliense, 1987.

Rua de mão única. Obras

Charles Baudelaire: um lírico no auge do capitalismo. Obras escolhidas, vol. III. São Paulo: Editora Brasiliense, 1995.

DRUMMOND DE ANDRADE, Carlos. Discurso de primavera e algumas sombras. Posfácio Sérgio Alcides. São Paulo: Companhia das Letras, 2014.

GRAMSCI, Antonio. Cadernos do cárcere. Volume II. Rio de Janeiro: Civilização Brasileira, 2006.

KRENAK, Ailton. Ideias para adiar o fim do mundo. São Paulo: Editora: Companhia das Letras, 2019.

MILANEZ, B.; WANDERLEY, L. J. O número de barragens sem estabilidade dobrou, "e daí?". Versos, v. 4, n. 4, 2020.

ROMERO, Sérgio Luiz G. Gimenes. A economia no meio do caminho: mineração e endividamento no Drummond da década perdida. Literatura: teoría, historia, crítica, vol. 22, $\mathrm{n}^{\circ} 2$, p. 127-151, 2020.

WANDERLEY, Luiz Jardim. Do Boom ao Pós-Boom das commodities: o comportamento do setor mineral no Brasil. Versos, vol. 1, n 1, p. 1-7, 2017.

ZHOURI, Andréa et al. "O desastre do Rio Doce: entre as políticas de reparação e a gestão das afetações". In: ZHOURI, Andréa (org.). Mineração: violências e resistências: um campo aberto à produção de conhecimento no Brasil. Marabá, PA: Editorial iGuana; ABA, 2018. e-PUB. p. 28-64. 